\title{
Sobre derecho y sociedad en Jorge Millas
}

\section{About law and society in Jorge Millas \\ Sobre direito e sociedade em Jorge Millas}

Dr. Maximiliano Figueroa ${ }^{1}$

Recibido: 31/07/2014 - Aceptado: 10/09/2014

\begin{abstract}
Resumen
Este artículo es una valoración del derecho que el filósofo chileno Jorge Millas hace desde la perspectiva socio-cultural. Analiza el aporte y función del derecho para el despliegue de la moderna sociedad de masas.
\end{abstract}

Palabras clave: Filosofía chilena - Jorge Millas - Derecho - sociedad de masas - derechos sociales

\section{Abstract}

This article is an assessment of law that the Chilean philosopher Jorge Millas presents from the socio-cultural perspective. It analyzes the contribution and role of law for the deployment of the modern mass society.

Key words: Chilean philosophy - Jorge Millas - law - mass society - social rights

\section{Resumo}

Este artigo é uma estimação do direito que o filósofo chileno Jorge Millas faz da perspectiva sociocultural. Analisa a contribuição e papel do direito para a expansão da moderna sociedade de massa.

Palavras-chave: Filosofia Chilena - Jorge Millas - Direito - Sociedade De Massa - Direitos Sociais.

1 Doctor en Filosofía Moral y Política, Universidad de Deusto, España. Académico del Departamento de Filosofía de la Facultad de Artes Liberales de la Universidad Adolfo Ibáñez. Contacto: maximiliano.figueroa@uai.cl 


\section{Introducción}

Jorge Millas (1917-1982) estudió historia, derecho y filosofía en la Universidad de Chile. A esta institución estuvo ligado largos años. Fue Presidente de la FECH entre 1938 y 1939 apoyado por el Partido Socialista. En 1951, luego de realizar estudios de postgrado en EEUU, de su paso como profesor visitante en la Universidad de Columbia y de su desempeño académico en la Universidad de Puerto Rico, se incorporó como profesor del Departamento Central de Filosofía y Letras de la Facultad de Filosofía y Educación y llegó a ser su director entre los años 1960-1967. Dictó la cátedra de Filosofía del Derecho en la Facultad de Ciencias Jurídicas hasta 1975, año en que tuvo que renunciar luego de publicar un artículo en que acuña la expresión "universidad vigilada" para representar la situación que vivían las universidades chilenas después del 11 de septiembre de 1973. En 1978 es uno de los 12 firmantes del acta fundacional de la Comisión Chilena de Derechos y Humanos y en 1980 funda y preside, por elección de sus miembros, la Academia Universitaria Andrés Bello, destinada a la defensa de las instituciones de educación superior. Su último vínculo institucional fue con la Universidad Austral, a la que también se vio obligado a renunciar en 1981, un año antes de su muerte, como exigencia de su propia conciencia y de la hostilidad que experimentó luego de convertirse, en ese momento, en el más importante intelectual crítico frente a la dictadura militar.

Este artículo está dedicado a recuperar pasajes de la obra del pensador chileno en que es posible reconocer su consideración del derecho desde la perspectiva del desarrollo de la sociedad occidental. En su libro Filosofía del derecho, Millas establece cuatro órdenes de problemas que rebasan los límites de todos los departamentos particulares de la ciencia jurídica: i) ¿Qué es el derecho? ii) ¿Cuáles son, si los hay, los conceptos y principios a priori del conocimiento jurídico? iii) ¿Cuáles son los fines de las normas ideales y los valores del derecho? iv) ¿Cuál es la situación, y cuáles son las conexiones fundamentales 
del derecho, en el seno de la realidad universal?². Este último asunto es el que ocupa este trabajo, y que si bien no lo agota, se inscribe en su ámbito.

Con la excepción del importante aporte de Agustín Squella y otros contados casos, entre los últimos se puede mencionar a Juan O. Cofré, el estudio y análisis crítico de la obra jurídica de Jorge Millas ha tardado en producirse. Su enfoque, expresado en su docencia y en su producción escrita, fue reconocido como un aporte valioso por quienes, como sus alumnos, escucharon directamente sus lecciones, y por quienes, como sus lectores, le prestaron atención inmediata a sus textos. Entre los primeros, considérese el siguiente testimonio del novelista Jorge Edwards: "En mi quinto año de la Escuela de Leyes de la calle Pío Nono, y esto debe haber ocurrido en 1953 o 1954, escogí el curso de Jorge Millas en la asignatura de Filosofía del Derecho. No podría repetir detalles y mis apuntes deben de estar podridos en algún subterráneo del centro de Santiago, pero sé que fue un curso memorable, inspirador, estimulante, lleno de grandes momentos de reflexión. Yo era un alumno más bien ausente de los ramos normales, conquistado ya por los morbos conjugados de la lectura y escritura, pero sé que nunca me perdía las clases que dictaba el profesor Millas en una pequeña sala del tercer piso, ante pocos alumnos, en la última hora de la mañana. Con él se desdeñaba la manía, dominante en aquella escuela y en todo el país, de memorización de las materias, y se intentaba comprender el sentido último de la norma jurídica, el concepto de justicia, las nociones de Estado de derecho. Se hablaba de la posibilidad de una democracia moderna y de los equilibrios y los controles que ella exigía. Y se hacía la crítica de los dogmatismos y los conformismos al uso, tanto de un extremo como de otro. Ese curso de filosofía del derecho [...] en medio de una época de simplismos, de reduccionismos abusivos, era orientador y aleccionador. Jorge Millas hacía una invitación permanente a reflexionar con independencia, con auténtica libertad, sin dejarse llevar por las corrientes en boga.

2 Millas, Jorge. Filosofía del derecho (Comentarios, notas y edición de Juan O. Cofré), Ediciones Universidad Diego Portales, Santiago, 2012. 
Hoy día me parece que no le prestamos, y no sólo me refiero a esa docena y media de alumnos sino a toda mi generación, la atención suficiente, y estoy convencido de que eso nos obligó a perder muchos más años de los necesarios" ${ }^{3}$.

Entre los segundos, el jurista Raúl Rettig -quien presidió la comisión Verdad y Reconciliación durante el retorno a la democracia- estimó la obra jurídica de nuestro autor de esta manera: "Millas llegó a la altura en que el aporte doctrinal de otros se recibe con intención crítica, se relava en la intimidad propia y, así depurado, se exhibe a los demás previa declaración de qué extremos se rechazan y de qué substancias se adoptan para enriquecer un patrimonio conceptual. Más que destinado a ser discípulo, Millas fue maestro, constructor y creador. Como filósofo del Derecho, Millas tiene hallazgos que requirieron, precisamente...de Jorge Millas, para proyectarse en el ámbito tan estrecho entre nosotros del estudio teórico de lo jurídico en profundidad. Su noción acerca de la plasticidad axiológica del Derecho nos revela cómo todos los valores buscan la tutela de la norma. Y, al decirlo, lo hace con originalidad y belleza. El concepto de seguridad jurídica como valor supremo que el Derecho debe custodiar, y con el cual llega a una identificación casi esencial, está en sus obras con rigor y seriedad tales que hacen irrebatible la postulación formulada" ${ }^{4}$.

La reedición de su Filosofía del derecho, en el año 2012, por las ediciones de la Universidad Diego Portales, institución comprometida con la recuperación de la obra del filósofo, aporta una accesibilidad a sus ideas jurídicas que se requería para el más amplio conocimiento y estimación de éstas. En este escrito -riguroso en su propósito de delimitación categorial de la estructura y esencia del derecho, solidario con la tarea indicada por Kelsen de entender jurídicamente lo jurídico, de purificar los conceptos con que el derecho ha de ser pensado para dar con su inconfundible índole-, Millas se abre a

3 Edwards, Jorge. "El improvisador discordante", en Squella, A. (ed.). En recuerdo de Jorge Millas. Revista de Ciencias Sociales, Facultad de Derecho y Ciencias Sociales, Universidad de Valparaíso, n 49-50, Valparaíso, 2004-2005, pp. 55-56.

4 Rettig, Raúl. "Jorge Millas", Las Últimas Noticias, 16 de noviembre de 1982, p. 5. 
reconocer que tal empresa no puede, aunque sea por la necesidad de su consecución, hacernos perder de vista que no es la única perspectiva para considerar el derecho y que "constituye sólo una etapa técnica de otra mucho más amplia, más difícil y quién sabe si también más útil: la de comprender el derecho dentro del orden universal de las cosas con que se $\mathrm{da}^{\prime \prime}$.

El hecho de que este trabajo atienda a parte de los esfuerzos de Millas por comprender el derecho en el contexto amplio de la experiencia humana, específicamente en su significado y relevancia histórica y moderna, explica que la atención no esté puesta en el libro Filosofía del derecho sino en otra serie de textos que expresan el punto de vista privilegiado. Las dos tesis que aquí se sostienen, permiten organizar parte importante de las consideraciones que Millas realiza sobre el derecho en su conexión con el despliegue histórico de la sociedad occidental. Son las siguientes: i) El derecho representa de manera privilegiada la vocación racional de Occidente y ii) el derecho en la sociedad contemporánea está animado en su concreción por el objetivo de dar salvaguarda y promoción a la dignidad humana de los individuos.

\section{Primera tesis. El derecho es una concreción de la vocación racional de Occidente}

Una vez egresado de la Universidad de Chile, Jorge Millas realiza estudios de postgrado en Estados Unidos como becario de la Fundación Guggenheim y del Instituto Internacional de Educación. Obtiene el Master of Arts en Psicología por la State University of lowa en 1945 y realiza también estudios en la New School for Social Research en Nueva York. La Universidad de Puerto Rico, al final de este período formativo, lo contrata por cinco años (entre 1946 y 1950) para que se aboque a un trabajo de promoción de las humanidades a través de la

5 Millas, Jorge. Filosofía del derecho (edición de Juan O. Cofré), Ediciones Universidad Diego Portales, Santiago, 2012, p. 157. 
dirección de los Cursos Básicos que formaban parte del programa de Estudios Generales que recibían todos los alumnos por un período de dos años. El objetivo de estos cursos era proporcionar a los estudiantes universitarios una formación inicial de carácter humanista que les permitiera conocer en su "espíritu" las grandes líneas del desarrollo de la cultura occidental; se trataba, en palabras del propio Millas, de contribuir al "cultivo integral de la personalidad intelectual y afectiva del hombre, que cada vez se hace más ineludible a la educación contemporánea" ${ }^{\prime 6}$.

El pensador chileno asumió la concepción y concreción de este programa: dictó cursos, formó profesores, redactó material de estudio, en fin, se comprometió en una empresa que le permitió definir ideas pedagógicas y formativas que se proyectarían en su visión de la universidad y en su compromiso personal con esta institución. El libro Ensayos sobre la historia espiritual de Occidente, publicado en Chile en 1960, reúne una primera serie de escritos que plasman lo que fue la experiencia docente e intelectual en Puerto Rico; otras dos series, prometidas por el propio Millas en el Prefacio, no llegaron a publicarse; una dedicada a la experiencia intelectual y otra a la experiencia político-social de Occidente. Ensayos sobre la historia espiritual de Occidente es una obra extraordinaria cuyo conocimiento y divulgación representaría, sin lugar a dudas, un aporte enriquecedor en los esfuerzos por dotar a la formación universitaria de amplitud cultural y de un sentido humanista crítico y reflexivo.

Este libro merece atención porque en él Millas plasma su idea de la significancia cultural del derecho a propósito de un magistral balance que realiza del aporte espiritual de Roma. Si el genio griego se destacó por su carácter especulativo, el romano -sostendrá- fue eminentemente práctico, se inclinó original y primordialmente al manejo de las cosas antes que a la búsqueda de una explicación exhaustiva de ellas. "Ahí donde los griegos pusieron el ideal de la reflexión inte-

6 Millas, Jorge. Ensayos sobre la historia espiritual de Occidente, Editorial Universitaria, Santiago, 1960, p. 31. 
riorizadora del hombre, situaron los romanos el de la organización exterior de su conducta; ahí donde las griegos pusieron la tarea de la ciencia y la filosofía, instalaron los romanos la del Estado universal y del Derecho"7. El derecho, afirmará el filósofo, "es el más acabado de los productos culturales de Roma, aquél en que el romano dio lo mejor de sí y se expresó con más acentuada originalidad" ${ }^{8}$. Desde el punto de vista del desarrollo histórico, el aporte romano fue ofrecer un sistema de derecho con la pretensión de fundarse en su valor intrínseco, antes que en su poder coactivo. Hubo orden de leyes antes de Roma, pero sólo con ella, o desde ella, se introdujo de manera decisiva el proceso de la desubjetivización de las relaciones del poder dentro de la sociedad. Roma abrió el camino de una ordenación jurídica por la cual la relación entre las personas deja de regirse por variables subjetivas para quedar éstas referidas en sus aspectos de mayor relevancia social a una norma preexistente y cognoscible. La específica grandeza romana estuvo en vincular dos cosas que no son a priori coincidentes: el orden del derecho y la asociación política. Al concretar esta vinculación Roma dio testimonio de una dirección espiritual que el tiempo registra, transcurridos ya algunos siglos, como una constante: la de la racionalidad, universalidad y moralidad del orden jurídico. Millas logra entrever el potencial universalista de esta experiencia y permite juzgarlo como una referencia para los tiempos modernos en que se multiplican los procesos de interconexión entre países reclamando determinaciones de orden legal para sus relaciones, referencia, también, en un proceso que conducirá, avanzada la modernidad, al universalismo pretendido de la declaración de los derechos humanos. A juicio de Millas, "el principio iusnaturalista fue el instrumento que permitió a la hazaña política de Roma convertirse en hazaña jurídica: la idea de una sociedad universal encontró su apoyo en la de un derecho universal" ${ }^{\prime \prime}$. Roma habría puesto una idea que quedó a la vista de los siglos de Occidente, la idea del derecho como la sustancia común de la comunidad. En tanto Roma fue una

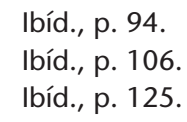


sociedad de horizonte cosmopolita, sostiene Millas, se explica que en ella llegara a forjarse el "ideal ecuménico del hombre".

Volviendo a la arquitectura interna del derecho romano, esta implica una enseñanza que está asociada a la visión que fija su articulación: "la sociedad se organiza políticamente cuando toda voluntad particular dentro de ella -la de los ciudadanos y de sus agrupaciones privadas-se supedita a una voluntad central soberana", pero que sólo hay relaciones de derecho cuando esta supeditación política es susceptible de una plenaria objetivación mediante un estatuto regulador preexistente, cuyo sentido pertenezca a un medio común, intersubjetivo, de significaciones ${ }^{10}$. Tendencia a la objetivación o racionalización de la vida en sociedad, es la ruta abierta en Occidente por el derecho romano, por cierto con vaivenes y entre avatares diversos, y que llega a la idea moderna del Estado de Derecho como a su máxima expresión. Lo que comanda este proceso, Millas lo vio de manera preclara: excluir al máximo, y en sus variadas formas, el despotismo. Dice Millas: "No basta que haya normas que operen objetivamente, una vez creadas; es menester, además, que el acto creador no sea subjetivo, no sea, por ejemplo, decisión privada del gobernante atrabiliario, ni inspiración del oráculo, ni "sabia" intuición del jefe iluminado. El orden jurídico pleno intenta excluir, de este modo, al máximum posible, hasta las más sutiles formas del despotismo"11.

A mi juicio, este pasaje de Millas puede ser interpretado como la afirmación de que existe un proceso histórico, asociable al desarrollo del derecho, en que el decantado que se expresa como exclusión del despotismo es la exclusión creciente, en el fondo, del recurso a la violencia en la construcción de la sociedad. Desde este punto de vista, proceso de racionalización de la vida social vendría a significar proceso de retroceso de la violencia en la organización socio-política.

Para Millas, resulta de esta manera evidente que no todo orden político es necesariamente un orden jurídico. "Aun allí en donde la subjetivi-

10 Ibíd., p. 103.

11 Ibíd., p. 104. 
dad del déspota se objetiva en normas, que adquieren la calidad de estatuto preexistente, el derecho no está plenariamente constituido, porque el acto generador del orden -la voluntad, benevolente o no, del gobernante- no se encuentra auto-vinculado, sujeto por modo imperativo a sus propias normas"12. "El estado de derecho implica, en realidad, el sumo grado de racionalización de la sociedad política y, en cuanto tal, es una creación característica de la vocación racional de Occidente"13. Es la gran conclusión del filósofo.

En el texto de 1975, "las máscaras filosóficas de la violencia"14, revisa Millas la noción de "violencia institucionalizada"; se trata de uno de los pasajes quizá más polémicos de nuestro autor. Recuperemos brevemente la argumentación. Millas, que ha pasado revista a las diversas razones que ideológicamente se dan para justificar el uso de la violencia política y pretender su legitimidad, señala que otro recurso argumentativo que suele darse consiste en el de aquellos que justifican su violentismo escudándose en que la sociedad organizada es ya una violencia; postulan que, específicamente, el orden del derecho representa un dispositivo social de violencia. Se suele decir, desde esta posición, lo siguiente: la violencia "sólo nos llama la atención y nos alarma cuando se manifiesta fuera y contra del orden establecido; pero, en cambio, la admitimos y nos conformamos con ella cuando se expresa dentro y a favor de ese orden, esto es, cuando está "institucionalizada". Estamos frente a lo que Millas denominó falacia del género sumo, falacia que consiste en detenerse en una idea general y aplicarla omitiendo las diferencias específicas necesarias de atender: siempre hay "violencia", sólo que a veces se trata de la violencia "institucionalizada", y a veces, de la violencia "no-institucionalizada", rezaría el argumento. Una de las doctrinas filosófico-políticas que más ha recurrido a este argumento justificador de la violencia contra el orden social, ha sido el anarquismo que, como sabemos, goza de una significativa revitalización.

12 Ibíd., p. 104.

13 ídem.

14 Millas, Jorge. "Las máscaras filosóficas de la violencia", Dilemas: revista de ideas, Universidad de Chile, Santiago, 1975, pp. 2-30. 
Millas es especialmente enfático frente a este planteamiento: se trata, según su punto de vista, de una incoherencia, pues "desde el momento que la violencia se institucionaliza -esto es, se somete a un sistema normativo, o, con más precisión, al orden jurídico-, ya no es violencia". A su juicio, cabe hablar de fuerza institucionalizada, pero no de violencia institucionalizada. Es cierto, y Millas no lo niega, que los ordenamientos del Derecho degeneran o pueden degenerar $y$, entonces, puede llegar a ocurrir que la fuerza del Estado encargado de proteger de tales anomalías se convierta relativamente en violencia. En ese caso, "el grado de relatividad es función del grado en que dicha fuerza se sustrae a las regulaciones del orden. Si la sustracción es total, se ha instalado en el derecho, la violencia, sin más"15. Para Millas la violencia es, dicho con precisión, la fuerza libre que simplemente no puede ser llevada a la jurisdicción reguladora de un ordenamiento jurídico y moral y seguir siendo tal. "Violencia institucionalizada" representa una contradicción en los términos y remite, cuando se le confiere plausibilidad, a un orden jurídico que ya no opera con propiedad, no de manera íntegra o cabal.

¿Cómo entender este planteamiento de Millas en circunstancias que el propio contexto en que se formula ofrece ejemplos de Estados que, no desprovistos de ordenamientos jurídicos, presentan el despliegue de una violencia dirigida a atropellar la dignidad y la vida de muchas personas? Terrorismo de Estado o violencia de Estado, ¿no son nociones que parecen hacer sentido a la luz de la experiencia de tantas víctimas de regímenes dictatoriales o totalitarios? Creo que Millas no dudaría en atribuir la violencia a esos regímenes, pero, quizás, dudaría respecto a si cabe considerarlos auténticos ejemplos del ordenamiento en los marcos del derecho y de su institucionalidad correspondiente. La explicación de este planteamiento se inscribe en el contexto del proceso que hemos tratado de describir en este trabajo y obliga a explicitar otros momentos de la reflexión jurídica de Millas. Habría que decir, en primer lugar, que el planteamiento taxativo de Millas se explica si se tiene a la vista que el propósito de

15 Ibíd., p. 7. 
su ensayo es delimitar el fenómeno y el concepto de la violencia en su especificidad. En segundo lugar, si se acepta que al separar Derecho de violencia, opera desde una determinada concepción del Derecho que sería tributaria del desarrollo histórico de esta creación humana y de su decantado contemporáneo en la moderna sociedad democrática occidental, que es al que, reitero, hemos estando aludiendo en este trabajo. Millas sostiene que "el Derecho es manifestación exterior visible de estados más profundos del alma social. Pero como toda expresión de vida colectiva, su acción reflejante es, a la par, una toma de conciencia, apta para reobrar sobre la propia cosa reflejada. Las instituciones del Derecho en sus dos aspectos de conducta social regulada (experiencia jurídica) y de su norma (representación normativa de aquella conducta) ponen ante la sociedad su propia imagen y coadyuvan, mediante la toma de conciencia que de esta manera inducen, a otras fuerzas rectificadoras. Y ello, sobre todo, si aquella imagen traduce también de algún modo como política jurídica, la acción de reforma"16.

Tales palabras vienen a expresar conclusivamente un análisis del desarrollo histórico del Derecho en la modernidad. El filósofo conecta la conformación del Derecho con la circunstancia de que "una sociedad no puede sobrevivir sin una representación adecuada de su estructura y dinámica, que procure a la conciencia de sus miembros unos principios de valoración reguladora y de seguridad dentro de la complicada urdimbre social" ${ }^{\prime \prime}$. Es interesante notar que esta idea contextualista del derecho está presente como idea decisiva en la construcción de la idea de justicia como equidad de John Rawls en su libro Liberalismo político. En este esquema representativo, se habría ido imponiendo, es lo que interpreto en Millas, un tipo de sociedad que en su autoimagen entiende el Derecho como la ordenación jurídico-normativa instituida para encauzar la convivencia humana

16 Millas, Jorge. "Derecho y sociedad de masas", Primeras Jornadas Sociales, Seminario de Derecho Privado de la Facultad de Ciencias Jurídicas y Sociales de la Universidad de Chile, Santiago, 1964, p. 24.

17 Ibíd., p. 23. 
en los mayores grados posibles de racionalidad y no violencia. Si, desde un punto vista general (y podría decirse que epistemológico), la postura de Millas también indica que en el marco del Derecho la coacción, la sanción y la pena son recursos a un tipo de fuerza que no se da libre, sino regulada, organizada y graduada; en el específico caso del Derecho instituido en una sociedad democrática, éste queda, y de modo especial su recurso a la fuerza, ordenado esencialmente a tal sociedad como contexto axiológico que determina su carácter y orienta su fijación y administración supeditándolo a la protección de la dignidad e integridad de las personas. Es este contexto axiológico y político el que permite afirmar taxativamente la incongruencia de una noción como "violencia de Estado". La aparente plausibilidad de la expresión vendría a indicar directamente la alteración negativa que se está verificando en el orden de las cosas, es decir, hablaría de un proceso de deterioro o corrupción que experimenta el Estado, la señal de un Estado contrahecho, carcomido en su índole política y moral. Eso es lo que Millas estimó que ocurría en Chile durante el régimen militar. Consultado en una entrevista periodística sobre si existen formas indirectas de terrorismo, respondió: "Las oficiales, las que tienen lugar en una forma clandestina en nombre de la ley, o mejor, en nombre de la autoridad. Cuando a una persona se la hace desaparecer de su casa, por ejemplo, por diez o más días y nadie sabe nada, no se sabe dónde encontrarla, ésa es una forma de amedrentamiento y opresión. Para mí, espantosa"18.

Esta exclusión de la violencia, por ejemplo en la forma política de la tiranía, es lo que Jorge Millas interpretó como un factor histórico impulsor de la ley o del Derecho. La tiranía es fuerza libre, arbitraria, sin sometimiento a control o norma, es violencia; por eso la libertad, en su necesaria evitación de la tiranía, acaba instituyendo un compromiso de la libertad con la libertad: el sistema del derecho, dicho más claro aún, el Estado de derecho.

18 Entrevista, "Terrorismo. Habla el filósofo Jorge Millas", La Últimas Noticias, 1 de marzo, 1981, p. 22. 


\section{Segunda tesis. El derecho en la sociedad contemporánea está animado en su concreción por el objetivo de dar salvaguarda y promoción a la dignidad humana de los individuos}

Una explicación completa de lo que implica esta tesis obliga a examinar dos momentos de la producción de Jorge Millas: i) su concepción del desafío que la sociedad de masas implica para el derecho y ii) su fundamentación de los derechos humanos que permite vincularlos con el sistema democrático como su condición de posibilidad. El segundo momento lo he desarrollado en mi libro Jorge Millas. El valor de pensar ${ }^{19}$. Además ha sido objeto de un magistral estudio por parte del profesor Humberto Giannini2 ${ }^{20}$. Por lo tanto, sólo me abocaré a esbozar el primer momento. El prisma de Jorge Millas, en este punto, posee una extraordinaria pertinencia en vista de los debates que están teniendo lugar en el Chile contemporáneo. En 1962 el pensador publicó una penetrante interpretación de la sociedad moderna en curso en su libro El desafío espiritual de la sociedad de masas. Esta obra contiene, específicamente, la meditada reacción del filósofo chileno frente al fenómeno de la masificación que caracteriza la tecnificada sociedad moderna.

Un análisis de la literatura respectiva, permite distinguir dos grandes fuentes intelectuales en la teoría de la sociedad de masas: una está ligada a la reacción que se produce en el siglo XIX ante los cambios revolucionarios de la sociedad europea, y la otra, a la reacción en el siglo XX ante el surgimiento del totalitarismo. La primera fuente puede denominarse crítica aristocrática a la sociedad de masas, y la segunda, crítica democrática. La crítica aristocrática tiene la mayor producción y representa una reacción ante la constatación de la pérdida de exclusividad y poder por parte de las élites y la emergencia

19 Figueroa, Maximiliano. Jorge Millas. El valor de pensar, Ediciones Universidad Diego Portales, Santiago, 2011, Capítulo III: "Democracia y Derechos Humanos".

20 Giannini, Humberto. "Acerca de la dignidad del hombre", Anuario de Filosofía Jurídica y social, Sociedad Chilena de Filosofía Jurídica y Social, Valparaíso, 1984. 
de las masas en la vida cultural y política. Representantes destacados son Burckhardt y Le Bon, en el siglo XIX, Karl Mannheim y Ortega y Gasset, en el siglo XX, entre otros. La crítica democrática también tuvo un sentido defensivo, en este caso respecto a los logros políticos conseguidos frente a las élites $y$, principalmente, ante el peligro que representaba la amenaza del totalitarismo. Son vinculables con esta crítica autores como Emil Lederer, Hannah Arendt y el sociólogo C. Wright Mills.

El desafío espiritual de la sociedad de masas se inscribe en esta escena representando un claro distanciamiento frente a la crítica aristocrática. Específicamente la de Ortega y Gasset, de quien Millas se declaró, en más de una ocasión, discípulo intelectual y lector apasionado. $L a$ rebelión de las masas, el libro que dio reputación europea a Ortega, aparece en 1928, pero las primeras reflexiones que lo conformarán salen a la luz el año 1926 en periódicos de Madrid. La pluma de Ortega describe de manera magistral el fenómeno de la emergencia de la sociedad de masas como asociado a la expansión y concentración cuantitativa de individuos en las ciudades modernas; se trata de la emergencia de las muchedumbres constatable ya visualmente. Sostendrá: "La muchedumbre, de pronto, se ha hecho visible, se ha instalado en los lugares preferentes de la sociedad. Antes, si existía, pasaba inadvertida, ocupaba el fondo del escenario social [...] El concepto de muchedumbre es cuantitativo y visual. Traduzcámoslo sin alterarlo a la terminología sociológica. Entonces hallamos la idea de masa social. La sociedad es siempre una unidad dinámica de dos factores: minorías y masas. Las minorías son individuos o grupos especialmente cualificados. La masa es el conjunto de personas no especialmente cualificadas [...] el hombre en cuanto no se diferencia de otros hombres, sino que se repite en sí un tipo genérico"21. Ahora bien, ¿por qué Ortega habla de "rebelión de las masas"? Las

21 Ortega y Gasset, J. La rebelión de las masas, Ed. Andrés Bello, Santiago, 1989, p. 55. Otros pasajes ilustran la postura crítica aristocrática de Ortega, interesantes por su carga valorativa y por su cercanía con un naturalismo que se vincula, a mi parecer, con su vitalismo de raigambre nietzscheana: ver p. 101. 
palabras del pensador español nos la recuerda el propio Millas: "Las masas se han hecho indóciles a la conducción de las minorías, no las obedecen, no las siguen, sino que, al contrario, las dan de lado y las suplantan"22. Esta rúbrica sintetiza el problema que advierte Ortega y nos muestra que lo hace como quien advierte un mal o amenaza de declive. Reparemos en otros pasajes: "Todo destino es dramático y trágico en su profunda dimensión. Quien no haya llegado a la entraña del destino, no ha hecho más que acariciar su mórbida mejilla. En el nuestro, el ingrediente terrible lo pone la arrolladora y violenta sublevación moral de las masas. La indocilidad política de las masas no sería grave si no proviniese de una más honda y decisiva indocilidad intelectual y moral. La masa, antiguamente, presumía que, al fin y al cabo, con todos sus defectos y lacras, las minorías de los políticos entendían un poco más de los problemas políticos que ella. Ahora, en cambio, cree la masa que tiene derecho a imponer y dar vigor de ley a sus tópicos de café. Yo dudo que haya habido otras épocas de la historia en que la muchedumbre llegase a gobernar tan directamente como en nuestro tiempo" ${ }^{\prime 23}$. El siguiente juicio es categórico como balance o perspectiva: "Es ilusorio pensar que el hombre-medio vigente, por mucho que haya ascendido su nivel vital en comparación con el de otros tiempos, va a poder regir, por sí mismo, el proceso de la civilización" ${ }^{24}$.

Millas relativiza la idea descrita por Ortega y pone en duda la afirmación de que un empoderamiento de las masas se esté efectivamente produciendo y, más aún, que sea la gran característica de nuestro tiempo. Dice: "Las masas cuentan hoy, es cierto, más que antaño. Su potencia de acción es formidable: hacen grandes números, llenan espacios, pueden mover y destruir la fábrica entera de la comunidad civilizada. Pero el poder, el poder, ¿lo ejercen ellas?". Millas en este punto es rotundo, y señala: "aunque las masas de hoy, a diferencia, quizá, de las de antaño, constituyen un factor importante del poder,

22 Millas, J. Op. Cit., p. 36.

23 Ortega y Gasset, J. op. cit., pp. 103-104.

24 Ibíd., p. 104. 
no lo tienen de verdad"25. A su juicio, lo que sí se ha producido es una separación tajante entre el sujeto del poder en sentido estricto (voluntad-designio de acción sigue radicada en minorías) y el sujeto de la acción misma, donde sí tiene un papel la masa. Millas se pregunta: "¿Qué son hoy, por ejemplo, las asociaciones gremiales de obreros, empleados y profesionales sino organizaciones con una enorme capacidad de acción, pero que, no obstante, carecen del verdadero poder?"26. El pensador adhiere completamente a los planteamientos del sociólogo norteamericano Wright Mills, a quien cita más de una vez, por ejemplo en este pasaje: "Los que suponen que las masas son todopoderosas o que, por lo menos, van en camino de serlo, están equivocados [...] La manipulación es el ejercicio secreto del poder, sin que se den cuenta de ello aquellos sobre los cuales influye" 27 . La tesis central de Mills, a la que Millas se suma, es que la sociedad de masas se caracteriza por el poderío de élites directoras, de minorías influyentes, cuya estrategia de mando consiste en hacer creer que la gente, que el hombre-medio, toma realmente las decisiones.

La reacción del pensador chileno, que se anuncia ya en el título de su libro, se aleja de la alarma y negatividad de Ortega y todos los representantes de la crítica aristocrática. Dirá: "La sociedad de masas representa un desafío al espíritu, por su magnitud el más serio que éste haya confrontado. El problema reside en encontrar para la nueva situación su correspondiente forma espiritual, mediante un régimen de valores, normas de contención y de empuje, jerarquía de bienes y elección crítica de rumbos ${ }^{281}$. La sociedad de masas es para Jorge Millas la oportunidad histórica de poner la vida real, el efectivo ser histórico del hombre, a la altura de su idea, a la altura de la dignidad atribuida. Esto significa, algo concreto, dar acceso a los bienes materiales y espirituales necesarios para la promoción de seres individuales 
protagonistas de sus vidas e involucrados en la construcción y rectificación del orden social al que pertenecen.

En la conferencia "Derecho y sociedad de masas", que luego será incluida en la edición norteamericana de El desafío espiritual, Millas reconoce, como ya hemos mencionado, que hay una tarea política que toda sociedad tiene de construcción moral de sí misma que permita su cohesión y proyección como comunidad. En este sentido, Millas pensaba que la sociedad de masas abría el derecho a una etapa nueva en la que se verificaría la transformación o ampliación del sentido de los derechos subjetivos. Pensó que la vieja gama de derechos que emergen en los orígenes de la sociedad liberal capitalista, se debiera enriquecer con la institución del derecho al trabajo, el derecho a la vivienda y el derecho a la educación. Y con una claridad que no puede sino interpelarnos, afirmó que tales derechos no pueden ser leídos como una franquía para la "libre" competencia por tales derechos, como sostendrían importantes corrientes de pensamiento contemporáneo como el neoliberalismo, sino como ejercicio efectivo de ellos por acción representativa de la sociedad. La sociedad asume los derechos individuales como tales en aras de su efectividad ${ }^{29}$, sostuvo, y al hacerlo, creemos posible sostener desde Millas, estaría requiriendo en su base la existencia de un acto deliberativo de la sociedad misma que llegue a plasmarse en el orden jurídico como expresión fiel de aquello que se quiere sea expresión de la autoimagen moral de la sociedad. En la realización de estos derechos, la sociedad se jugaría, parece haber pensado Millas, su índole democrática, las condiciones para una ciudadanía efectivamente real y una parte decisiva de la tarea espiritual de la sociedad de masas.

La razón de esta necesidad la expresó Millas en varios pasajes, uno de ellos elaborado en un análisis crítico de la teoría de la libertad de Friedrich Von Hayek. Básicamente, para lo que aquí nos ocupa, Millas piensa que existen serias insuficiencias, lógicas y éticas, en una

29 Millas, J. "Derecho y sociedad de masas", Primeras jornadas sociales, Seminario de Derecho Privado de la Facultad de Ciencias Jurídicas y Sociales de la Universidad de Chile, Santiago, 1962, pp. 23-25. 
concepción de la libertad que privilegia sólo lo que se conoce en la tradición liberal como "libertad negativa", es decir, que identifica el ser libre con la ausencia de coacción de otro sobre mí. Le parece que, siendo éste un aporte fundamental del liberalismo clásico, el desarrollo histórico exige abrirse a un concepto de libertad más complejo. El gran desafío ya no estaría sólo en dejar libre de coacción al individuo frente a una acción limitativa directa sobre él, sea del Estado, de otro individuo o grupo de individuos, sino de otorgar posibilidades ciertas para que éste pueda ejercer positiva y efectivamente su libertad como potencia de acción. Su rúbrica de esta idea es clara: "La libertad puede ser incrementada habilitando al hombre como individuo para tener mayor capacidad de opción".

Desde esta perspectiva, se puede señalar lo difícil que es sostener que puedan existir reales posibilidades para que un sujeto se desarrolle como individuo libre sin participar de ciertas condiciones u oportunidades mínimas que se lo permitan, condiciones que no pueden sino ser generadas social y políticamente y, en principio, de una manera accesible a todos: "La lucha por la libertad humana -sostendrá Millas en un párrafo que juzgamos fundamental en su análisis- sería en extremo insuficiente si no atendiera a la redención del individuo, que es un aspecto positivo de la libertad. Dicha redención se mira aquí, no como exigencia de un ideal de justicia, ni de paz, ni de respeto a la dignidad del hombre, sino como consecuencia de reconocer en la libertad un valor y de proponernos su realización. Redimir socialmente al individuo es incrementar su poder, es decir, su libertad. No otra cosa hacemos cuando enseñamos a leer al analfabeto, cuando abrimos más oportunidades para la educación profesional, cuando difundimos las artes y las letras; pero es también lo que hacemos al buscar las mejores condiciones posibles de salud, alimentación y vivienda para el común de los hombres, procurando el esfuerzo social para tales servicios, o la seguridad de remuneraciones mínimas. Las remuneraciones mínimas y la gratuidad de determinados servicios no son única ni principalmente procedimientos destinados a evitar que la fuerza de trabajo experimente merma; son también mecanismos de incremento de la libertad en su aspecto positivo: en su virtud se promueve el ascenso de nivel, o siquiera el mantenimiento de 
un nivel básico de expectativas, el incremento de la libertad como capacidad de hacer" ${ }^{\prime 30}$.

Este pasaje es especialmente interesante por la perspectiva que propone adoptar. No niega que la generación social de ciertas oportunidades para el desarrollo de los individuos sea algo postulable desde un cierto ideal de justicia, de paz, o desde el respeto a la dignidad del ser humano; lo que se afirma es que tal generación de oportunidades se deriva como un imperativo necesario, y por lo tanto ineludible, al considerar la libertad como valor central de la sociedad. Sería una tarea de coherencia de la sociedad consigo misma en su específica representación histórica, una tarea que la comprometería en su articulación política, institucional y jurídica.

Una última indicación, de carácter programático para el trabajo de quienes buscamos entender y ponderar la obra del filósofo chileno. El año 1966, Millas publica un artículo titulado "Aristóteles: la justicia como acción igualadora". A pie de página indica que se trata del cuarto capítulo que tendrá en su libro cuyo título adelanta: Idea de la Justicia. Y que, lamentablemente, no llegó a publicar. En este artículo, a través de un análisis lúcido y original de los escritos del estagirita, arriba a la conclusión de que lo justo necesita valerse de otro instrumento para lograr el aseguramiento de su pretensión; ese instrumento lo sintetiza, a su juicio, la idea de equidad. Esta idea sería especialmente relevante a la luz de lo que hemos expuesto en este artículo, porque Millas enfatiza la prioridad de la política y del Estado en la determinación de la justicia, algo que, ya en Aristóteles, aunque con las limitaciones históricas de efectuación conocidas por todos, estaba entrevisto de un modo claro y que el desarrollo de la sociedad contemporánea, declarativamente, asume como su sentido ético político basal: el Estado viene a representar la asociación desde la igualdad de los ciudadanos libres en vista del aseguramiento y posibilitación de la vida buena, en vista, especí-

30 Millas, Jorge. "La libertad-poder de Friedrich Von Hayk", en Anuario de Filosofía Jurídica y Social, Sociedad Chilena de Filosofía Jurídica y Social, Valparaíso, 1996, pp. 458-59. 
ficamente, de generar las condiciones que permitan su búsqueda individual de realización.

\section{Bibliografías}

Edwards, Jorge. "El improvisador discordante", en Squella, A. (ed.). En recuerdo de Jorge Millas. Revista de Ciencias Sociales, Facultad de Derecho y Ciencias Sociales, Universidad de Valparaíso, $n^{\circ}$ 49-50, Valparaíso, 2004-2005.

Figueroa, Maximiliano. Jorge Millas. El valor de pensar, Ediciones Universidad Diego Portales, Santiago, 2011.

Giannini, Humberto. "Acerca de la dignidad del hombre", Anuario de Filosofía Jurídica y social, Sociedad Chilena de Filosofía Jurídica y Social, Valparaíso, 1984.

Millas, Jorge. Ensayos sobre la historia espiritual de Occidente, Editorial Universitaria, Santiago, 1960.

"Derecho y sociedad de masas", Primeras jornadas sociales, Seminario de Derecho Privado de la Facultad de Ciencias Jurídicas y Sociales de la Universidad de Chile, Santiago, 1962, pp. 23-25

"Aristóteles: la justicia como acción igualadora", Editorial Jurídica de Chile, Santiago, 1967.

"Las máscaras filosóficas de la violencia", Dilemas: revista de ideas, Universidad de Chile, Santiago, 1975, pp. 2-30.

The Intelectual and Moral Challenge of Mass Society, Applied Literature Press, David Parent (traductor), Illinois State University, 1997.

Entrevista, "Terrorismo. Habla el filósofo Jorge Millas", La

Últimas Noticias, 1 de marzo, 1981.

"La libertad-poder de Friedrich Von Hayk", en Anuario de Filosofía Jurídica y Social, Sociedad Chilena de Filosofía Jurídica y Social, Valparaíso, 1996.

Filosofía del derecho. (edición de Juan O. Cofré), Ediciones Universidad Diego Portales, Santiago, 2012.

Ortega y Gasset, J. La rebelión de las masas, Ed. Andrés Bello, Santiago, 1989.

Rettig, Raúl. "Jorge Millas", Las Últimas Noticias, 16 de noviembre de 1982, p. 5. 